\title{
OPEN Structural, magnetic, and gigahertz-range electromagnetic wave absorption properties of bulk Ni-Zn ferrite
}

\begin{abstract}
M. Derakhshani ${ }^{1}$, E. Taheri-Nassaj ${ }^{1}$, M. Jazirehpour ${ }^{2}$ \& S. M. Masoudpanah ${ }^{3}$
Nickel-zinc ferrite $\left(\mathrm{Ni}_{0.5} \mathrm{Zn}_{0.5} \mathrm{Fe}_{2} \mathrm{O}_{4}\right)$ powders were prepared by the conventional solid-state route and sintered at 1100 and $1300^{\circ} \mathrm{C}$ for utilization as a tile electromagnetic wave absorber. Structural, magnetic, and microwave absorption properties were investigated by characterization techniques of X-ray diffraction, thermogravimetric analysis, Raman spectroscopy, electron microscopy, vibrating sample magnetometry, and vector network analyzer. The samples sintered at $1300^{\circ} \mathrm{C}$ showed high magnetic saturation of $87 \mathrm{emu} / \mathrm{g}$ and low coercivity of $4 \mathrm{Oe}$. Electromagnetic investigations exhibit

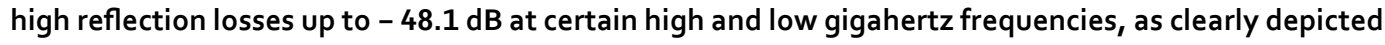
in the 3D contour plot. The optimized condition between reflection loss, thickness, and bandwidth revealed a reflection loss of about $-36.1 \mathrm{~dB}$ at the matching thickness of $3.7 \mathrm{~mm}$ for the X-band. Furthermore, the effective working bandwidth at $-10 \mathrm{~dB}$ was up to $\sim 7.1 \mathrm{GHz}$ for the minimum thickness of $4.3 \mathrm{~mm}$, which thoroughly covered the C-band. The microwave absorption performance of the well-sintered $\mathrm{Ni}-\mathrm{Zn}$ ferrite was attributed to the incorporation of dielectric and magnetic loss mechanisms in which the magnetic part prevails.
\end{abstract}

Wireless communication transmitting information from one point to another, without using any connection like wires, cables, or any physical medium, is widely used in mobile phones, GPS receivers, remote controls, and $\mathrm{Wi}-\mathrm{Fi}$, owing to its inexpensive, mobility, easiness, and reliability ${ }^{1,2}$. However, there are few drawbacks such as interference, security, and probable health issues for wireless communications ${ }^{3-5}$. The interference of electromagnetic (EM) waves from various devices can be led to high amounts of noise in connections by undesired constructive/destructive ways ${ }^{6-9}$. Among various methods, the shielding of electronic devices by microwave absorbers is an attractive and practical method to be safe against electromagnetic interferences and brings good electromagnetic compatibility (EMC) for the operating devices ${ }^{10,11}$. An ideal absorber material for electromagnetic interference (EMI) shielding should have high dielectric and magnetic losses, chemical stability, low-cost, and lightweight ${ }^{12,13}$.

Dielectric $^{14}$, magnetic ${ }^{15}$, and carbon-based ${ }^{16,17}$ materials could be utilized as EM wave absorbers in order to attenuate the distinct frequency range and reducing the interference caused by airborne connections ${ }^{18}$. In addition to the attenuation ability, which is related to dielectric and magnetic losses, another challenging issue is that an absorber material should fulfill the impedance matching condition $(z=\sqrt{\mu / \varepsilon} \sim 1)$ to receive incident EM waves with the lowest reflectivity. In most cases, absorber materials possess low permeability and high permittivity, while magnetic spinel ferrites have the competency of good impedance matching according to their higher permeability over other absorbers. Spinel ferrites $\left(\mathrm{MFe}_{2} \mathrm{O}_{4}, \mathrm{M}=\mathrm{Co}, \mathrm{Ni}, \mathrm{Mn}, \mathrm{Zn}, \mathrm{Fe}, \mathrm{Cu}\right)$ as soft magnetic materials can be used for diverse applications such as home and industrial electronic devices ${ }^{19,20}$, biomedicals ${ }^{21-23}$, catalysts $^{24,25}$, and further in EMI shielding as absorber materials because of their relatively high dielectric/magnetic loss, excellent chemical stability, and low costs ${ }^{26,27}$. Nickel-Zinc ferrite shows better EM wave absorption performances compared to other spinel ferrites due to higher resistivity, high saturation magnetization, and high permeability ${ }^{28-30}$. The spinel $\mathrm{Ni}-\mathrm{Zn}$ ferrite has a cubic crystal structure with the space group of Fd $3 \mathrm{~m}$ in which the cations are distributed between tetrahedral (A) and octahedral $[\mathrm{B}] \operatorname{sites}^{12}$. The occupation of (A) sites and

${ }^{1}$ Department of Materials Engineering, Tarbiat Modares University, 14115-143, Tehran, Iran. ${ }^{2}$ Department of Electroceramics and Electrical Engineering, Malek Ashtar University of Technology, Tehran, Iran. ${ }^{3}$ School of Metallurgy and Materials Engineering, Iran University of Science and Technology (IUST), Narmak, Tehran, Iran. ${ }^{\square}$ email: taheri@modares.ac.ir 


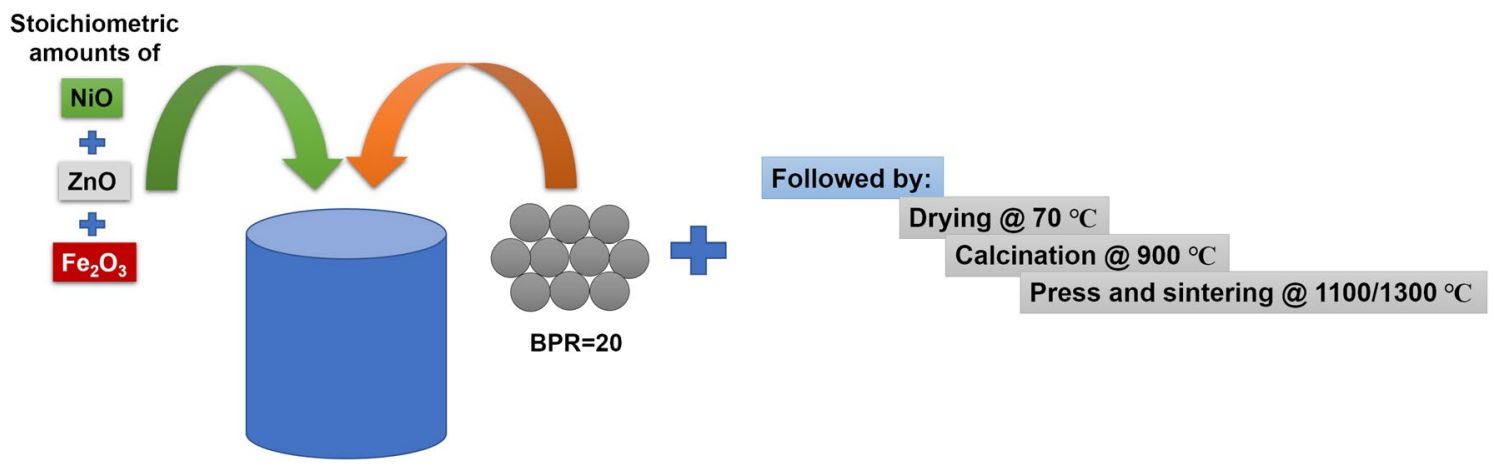

Figure 1. Schematic of the samples synthesis route.

[B] sites strongly depends on the ionic radius, crystal field, electron configuration, and ionic polarization of cations $^{31,32}$. Accordingly, the $\mathrm{Zn}^{2+}$ cations are usually preferred to occupy (A) sites because of crystal energy stabilization, while the octahedral [B] sites are appropriate for $\mathrm{Ni}^{2+}$ cations ${ }^{33,34}$. The $\mathrm{Fe}^{3+}$ cations can distribute between (A) sites and [B] sites due to the low crystal field energy stabilization ${ }^{35}$. The higher saturation magnetization (Ms) of $\mathrm{Ni}_{0.5} \mathrm{Zn}_{0.5} \mathrm{Fe}_{2} \mathrm{O}_{4}$ ferrites than that of $\mathrm{NiFe}_{2} \mathrm{O}_{4}$ ferrite is due to the higher difference of magnetic moments between (A) sites and [B] sites, which is induced by $\mathrm{Zn}^{2+}$ doping ${ }^{36,37}$.

$\mathrm{Up}$ now, alongside the reports on the electromagnetic properties of $\mathrm{Ni}-\mathrm{Zn}$ ferrite in the low frequency ranges $^{38-40}$, Huang et al. ${ }^{35}$ studied the magnetic and microwave absorption properties of paraffin/Ni-Zn nanofiber and expressed a magnetic saturation of about $77 \mathrm{emu} / \mathrm{g}$ and a reflection loss (RL) of - $14.1 \mathrm{~dB}$ at $10.9 \mathrm{GHz}$. Aggarwal and Narang ${ }^{41}$ investigated the $8.2-12.4 \mathrm{GHz}$ range electromagnetic properties of the nickel-zinc ferrite prepared by the sol-gel route and reached to minimum reflection loss of $-17.5 \mathrm{~dB}$ with the effective absorption band length of $3.1 \mathrm{GHz}$. Mustaffa et $\mathrm{al}^{42}$ scrutinized the microwave absorption properties of MWCNT/Ni-Zn composite and gained an $\mathrm{RL}=-19.3 \mathrm{~dB}$ with the bandwidth of $1.24 \mathrm{GHz}$ at $\mathrm{X}$ band frequency.

In microwave absorber application, spinel ferrite powders were usually prepared by a solid-state ${ }^{43,44}$ or a wet chemical route $e^{45,46}$ and mixed with different amounts of a suitable non-conductive or conductive polymer as the dispersant medium, and the composite mixture can be applied as coating ${ }^{47,48}$. The polymer/ferrite composites are disposed to destruct in harsh environments and do not have good durability as a permanent coating ${ }^{49}$. Moreover, it was mostly reported that the EM wave absorption performance might improve by maximizing the Ni- $\mathrm{Zn}$ ferrite content ${ }^{50,51}$, but the limitations of adding high amounts of ferrite powders besides the lack of integrity of the polymer-based coatings ${ }^{49}$, lead our team to investigate the microwave absorption properties of sintered $\mathrm{Ni}-\mathrm{Zn}$ ferrite in a wide $1-18 \mathrm{GHz}$ frequency range for utilization as tile absorber. Also, Naidu ${ }^{52}$ showed that bulk Ni-Mg ferrite has better microwave absorption properties than that of $\mathrm{Ni}-\mathrm{Mg}$ nanoferrites. In the present work, bulk $\mathrm{Ni}_{0.5} \mathrm{Zn}_{0.5} \mathrm{Fe}_{2} \mathrm{O}_{4}$ samples were fabricated by the conventional ceramic method, and the structural, microstructural, magnetic, and microwave absorption properties were studied as a function of sintering temperature.

\section{Experimental procedure}

The Ni-Zn ferrite powders were synthesized by the conventional solid-state method. Analytical grade of $\mathrm{Fe}_{2} \mathrm{O}_{3}$, $\mathrm{ZnO}$, and $\mathrm{NiO}$ powders in stoichiometric amounts (1:0.5:0.5) was mixed by using a planetary ball mill (Sanat Ceram, Iran) in a wet ethanol medium. The milling rotational speed was set at $200 \mathrm{rpm}$ for $7 \mathrm{~h}$ with the ball to powder ratio (BPR) of 20 . The obtained mixture was dried in the oven at $70{ }^{\circ} \mathrm{C}$ and then calcined at $900{ }^{\circ} \mathrm{C}$ in the air atmosphere. The calcined powders were ground again to break the large agglomerates. The as-calcined NiZn ferrite powders were uniaxially pressed into both disk-shaped $(\mathrm{d}=10 \mathrm{~mm})$ and toroidal ones $\left(\mathrm{d}_{\text {in }}=3 \mathrm{~mm}\right.$ and $\mathrm{d}_{\text {out }}=7 \mathrm{~mm}$ ) under the pressure of $250 \mathrm{MPa}$. The compacted bodies were sintered at 1100 and $1300{ }^{\circ} \mathrm{C}$ for $2 \mathrm{~h}$ in the air atmosphere. The schematic of the synthesis procedure is shown in Fig. 1.

Thermogravimetric analysis was operated with a simultaneous thermal analyzer (BAHR 504) from room temperature up to $1500{ }^{\circ} \mathrm{C}$ with the same condition used for calcination and sintering to show the thermal stability of the samples. The structural properties were characterized using an Ultima IV X-ray diffractometer (Rigaku, Japan) with $\mathrm{Cu} \mathrm{Ka}(\lambda=1.5406 \mathrm{~A})$ radiation. Crystal structure analysis of the XRD patterns was done using Highscore plus software, and the lattice parameter and cation distribution of the samples were calculated by the Rietveld refinement method. The nickel-zinc ferrite belongs to the spinel Fd3m space group; therefore, oxygen positions $(x=y=z)$ were taken as free parameters, while other atomic fractional positions were held as fixed. Moreover, lattice constants, isothermal parameters, occupancies, scale factors, and shape parameters were also taken as free parameters. Refinement steps were continued until the goodness of fit $\left(\sigma^{2}\right)$ reaches to the values close to 1.5 , showing the convergence of the refined profile with the observed patterns and confirming the quality of $\mathrm{fit}^{53}$. Cation distribution was obtained by taking into account the presence of both inverse and normal spinel structures. The nickel ferrite was modeled as complete inverse, while the zinc ferrite was considered as complete normal spinel. Furthermore, Raman spectroscopy was done using an XploRA PLUS (HORIBA, Japan) with a $785 \mathrm{~nm}$ laser line operated at room temperature. The microstructural characteristics were observed by a Mira 3 field-emission scanning electron microscope (TESCAN). An energy-dispersive detector with an accelerating voltage of $15 \mathrm{kV}$ was used to depict the elemental composition. A vibrating sample magnetometer (Meghnatis Daghigh Kavir Co., Iran) was used to measure the magnetic properties at room temperature. The applied field 


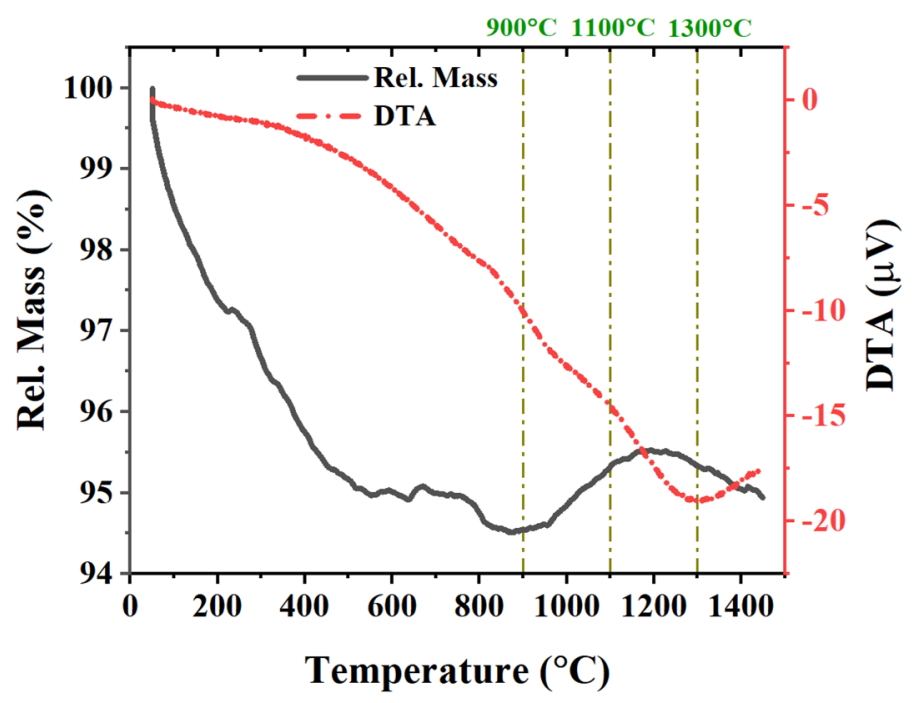

Figure 2. DTA/TG analysis results of the as-milled powders.

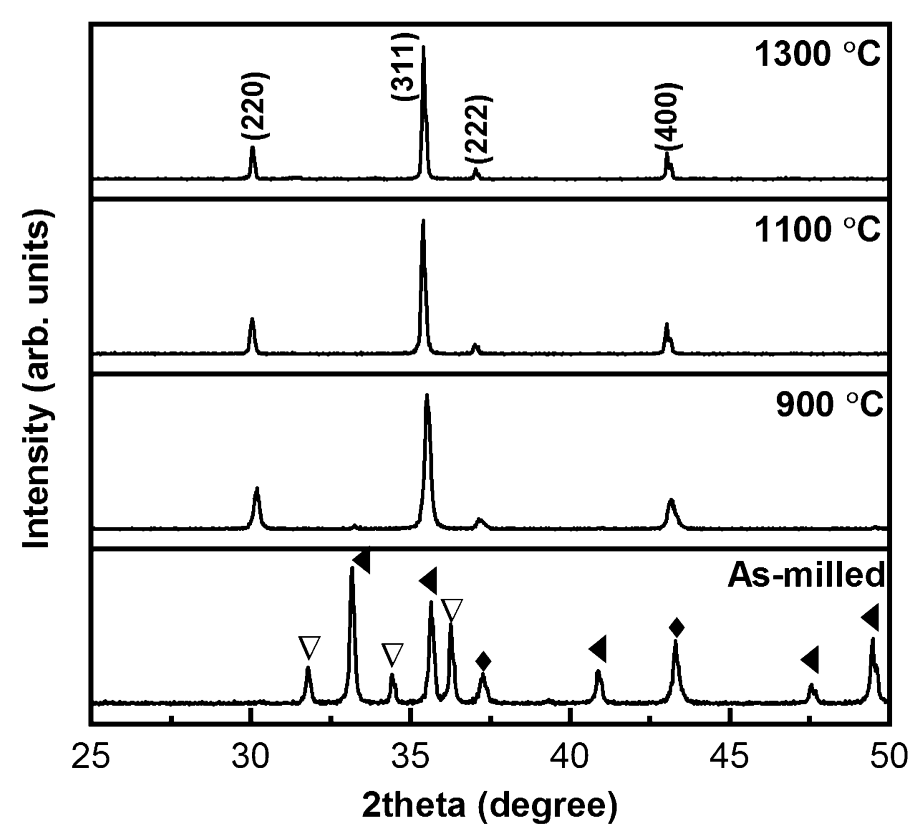

Figure 3. XRD patterns of the as-milled and calcined powders at $900{ }^{\circ} \mathrm{C}$ and the samples sintered at 1100 and $1300{ }^{\circ} \mathrm{C}\left(\nabla: \mathrm{ZnO}, \bullet: \mathrm{NiO}\right.$, and $\left.\bullet: \mathrm{Fe}_{2} \mathrm{O}_{3}\right)$.

was swept from - 10 to $10 \mathrm{kOe}$. Electromagnetic properties, including permittivity and permeability spectra, were obtained using an 8722 ES network analyzer (Agilent/HP) in the wide frequency range of 1-18 GHz.

\section{Results and discussion}

Figure 2 represents the DTA-TG plot of as-prepared powders. The initial mass reduction (about 5\%) starts from ambient temperature up to $600^{\circ} \mathrm{C}$ due to the elimination of physically absorbed water in most ( $3.5 \%$ up to $250{ }^{\circ} \mathrm{C}$ ) and dehydroxylation and decomposition of residual organic compounds. Three critical temperatures in TG curve at 900,1100 , and $1300^{\circ} \mathrm{C}$ were chosen for further thermal treatments of calcination and sintering where the main mass reduction occurs, spinel phase formation initiates, and sintering phase completes, respectively. Moreover, fluctuations of DTA curve at about 930,1120 , and $1280^{\circ} \mathrm{C}$ were attributed to the mentioned critical temperatures, where the broad endothermic peak at $1200-1400^{\circ} \mathrm{C}$ can also be assigned to the grain growth step of the sintering. Small fluctuations and negligible mass changes in the thermally analyzed sample illustrate the stability of the compound at higher temperatures ${ }^{54}$.

Figure 3 shows the XRD patterns of the initial mixture, as-calcined $\mathrm{Ni}-\mathrm{Zn}$ ferrite powder, and sintered samples. During the calcination process, the finely crushed $\mathrm{NiO}, \mathrm{ZnO}$, and $\mathrm{Fe}_{2} \mathrm{O}_{3}$ powders disappear by reacting the 


\begin{tabular}{|l|l|l|l|l|l|}
\hline Temperature $\left({ }^{\circ} \mathbf{C}\right)$ & $\mathbf{a}(\boldsymbol{\AA})$ & $\boldsymbol{\rho}_{\text {XRD }}\left(\mathbf{g ~ c m}^{-\mathbf{3}}\right)$ & Cation distribution & $\boldsymbol{\varepsilon} \times \mathbf{1 0}^{-\mathbf{3}}$ & $\boldsymbol{\delta} \times \mathbf{1 0 ^ { - 3 }}\left(\mathbf{n m}^{-\mathbf{2}}\right)$ \\
\hline 1100 & 8.3892 & 5.3486 & $\left(\mathrm{Ni}_{0.1} \mathrm{Zn}_{0.5} \mathrm{Fe}_{0.4}\right)_{\mathrm{A}}\left[\mathrm{Ni}_{0.4} \mathrm{Fe}_{1.6}\right]_{\mathrm{B}} \mathrm{O}_{4}$ & 2.06 & 0.03 \\
\hline 1300 & 8.3872 & 5.3525 & $\left(\mathrm{Ni}_{0.2} \mathrm{Zn}_{0.5} \mathrm{Fe}_{0.3}\right)_{\AA}\left[\mathrm{Ni}_{0.3} \mathrm{Fe}_{1.7}\right]_{\mathrm{B}} \mathrm{O}_{4}$ & 1.24 & 0.01 \\
\hline
\end{tabular}

Table 1. The lattice parameter, theoretical density $\left(\rho_{\mathrm{XRD}}\right)$, cation distribution, strain $(\varepsilon)$, and dislocation density $(\delta)$.

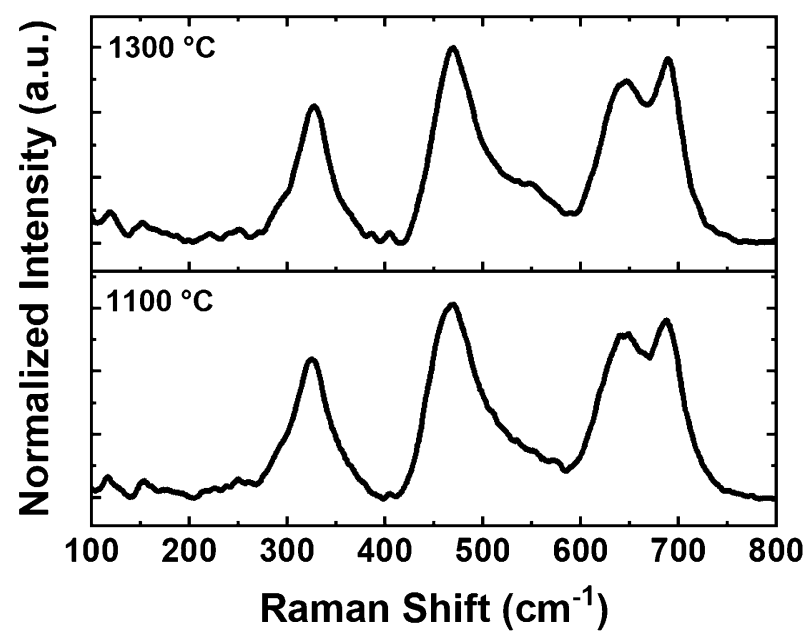

Figure 4. Raman spectra of the sintered samples.

\begin{tabular}{|l|l|l|l|l|l|}
\hline Temperature & $\mathbf{T}_{2 \mathrm{~g}}(\mathbf{1})$ & $\mathbf{E}_{\mathrm{g}}$ & $\mathbf{T}_{2 \mathrm{~g}}(\mathbf{2})$ & $\mathbf{T}_{2 \mathrm{~g}}(\mathbf{3}) /$ shoulder peak & $\mathbf{A}_{\mathbf{1 g}}$ \\
\hline $1100\left({ }^{\circ} \mathrm{C}\right)$ & 211 & 325 & 469 & 646 & 686 \\
\hline $1300\left({ }^{\circ} \mathrm{C}\right)$ & 212 & 326 & 469 & 648 & 688 \\
\hline
\end{tabular}

Table 2. Raman spectra peaks and related active modes.

$\mathrm{ZnO}$ species with $\mathrm{Fe}_{2} \mathrm{O}_{3}$ to crystallize the zinc ferrite $\left(\mathrm{ZnO} \mathrm{Fe}_{2} \mathrm{O}_{3}\right)$. After that, the $\mathrm{NiO}$ species slowly diffuses into zinc ferrite to produce NiZn ferrite $\left(\mathrm{Ni}_{0.5} \mathrm{Zn}_{0.5} \mathrm{Fe}_{2} \mathrm{O}_{4}\right)$ powders ${ }^{55,56}$. Therefore, the chemical reaction with stoichiometric ratios can be written as $0.5 \mathrm{NiO}+0.5 \mathrm{ZnO}+\mathrm{Fe}_{2} \mathrm{O}_{3} \rightarrow \mathrm{Ni}_{0.5} \mathrm{Zn}_{0.5} \mathrm{Fe}_{2} \mathrm{O}_{4}$. The diffraction peaks of the as-calcined powders and sintered samples at $2 \theta=30.04^{\circ}, 35.40^{\circ}, 37.03^{\circ}$, and $43.03^{\circ}$ are related to $(022),(311)$, (222), (004) planes of the spinel structure of $\mathrm{N}_{0.5} \mathrm{Zn}_{0.5} \mathrm{Fe}_{2} \mathrm{O}_{4}$ phase (PDF2\# 00-052-0278), respectively. Although a small peak of $\mathrm{Fe}_{2} \mathrm{O}_{3}$ phase was detected in the XRD pattern of calcined sample at $\sim 33^{\circ}$, the absence of any other peaks at higher temperatures confirms the purity of sintered $\mathrm{Ni}-\mathrm{Zn}$ ferrite samples. The lattice constant, density, cations distribution, dislocation density, and strain of the samples versus sintering temperature are shown in Table $1^{57}$. The lattice constant (a) decreases from 8.3892 to $8.3872 \AA$, while the density increases from 4.31 to $4.92 \mathrm{~g} \mathrm{~cm}^{-3}$ because of the reduction of crystal defects with the increase of sintering temperature. Distribution of cations show that the $\mathrm{Zn}$ cations are preferred to occupy tetrahedral (A) sites, while the Ni and Fe cations are distributed between tetrahedral (A) and octahedral $[B]$ sites in which the fraction of Fe cations in (A) site as inversion coefficient decreases from 0.4 to 0.3 with the sintering temperature.

Figure 4 shows the Raman spectra of the sintered samples at 1100 and $1300{ }^{\circ} \mathrm{C}$. Small and broad peaks at about $210,300,460,640$, and $680 \mathrm{~cm}^{-1}$ are related to the five active Raman modes of $\mathrm{T}_{2 \mathrm{~g}}(1), \mathrm{E}_{\mathrm{g}}, \mathrm{T}_{2 \mathrm{~g}}(2), \mathrm{T}_{2 \mathrm{~g}}(3)$, and $\mathrm{A}_{1 \mathrm{~g}}{ }^{58}$. Low Raman shifts revealed the presence of octahedral B-sties $\left(\mathrm{BO}_{6}\right)$, while the observed peaks at about $640-700 \mathrm{~cm}^{-1}$ are attributed to oxygen motion in the tetrahedral A-sites $\left(\mathrm{AO}_{4}\right)$ having $\mathrm{A}_{1 \mathrm{~g}}$ mode Raman character $^{59,60}$. This broad containing shoulder peak was also been assigned to the order-disorder effect of ions over A and B sites ${ }^{61}$. The related active Raman shifts presented in Table 2 confirms the formation of cubic spinel ferrite, $\mathrm{Fd} 3 \mathrm{~m}$, in the sintered samples. Also, all Raman peaks blue shifted slightly toward higher wavenumber due to the increase in sintering temperature (to $1300^{\circ} \mathrm{C}$ ), where the crystal defects and strain reduced and consequent lower lattice parameter values were obtained ${ }^{30}$.

FESEM micrographs and EDS analysis of the sintered samples at 1100 and $1300{ }^{\circ} \mathrm{C}$ are presented in Fig. 5. The samples sintered at $1100^{\circ} \mathrm{C}$ have small $(\sim 0.3 \mu \mathrm{m})$ and discrete grains, while the large grains $(\sim 10 \mu \mathrm{m})$ with smooth grain boundaries appear for sintering at $1300^{\circ} \mathrm{C}$. This may affect the magnetic and microwave absorption properties of the samples through the interface effects ${ }^{62,63}$. Also, it can be observed that the Ni-Zn ferrite particles cannot be grown and sintered at the lower temperature. Densification is chiefly related to grain boundary (GB) 

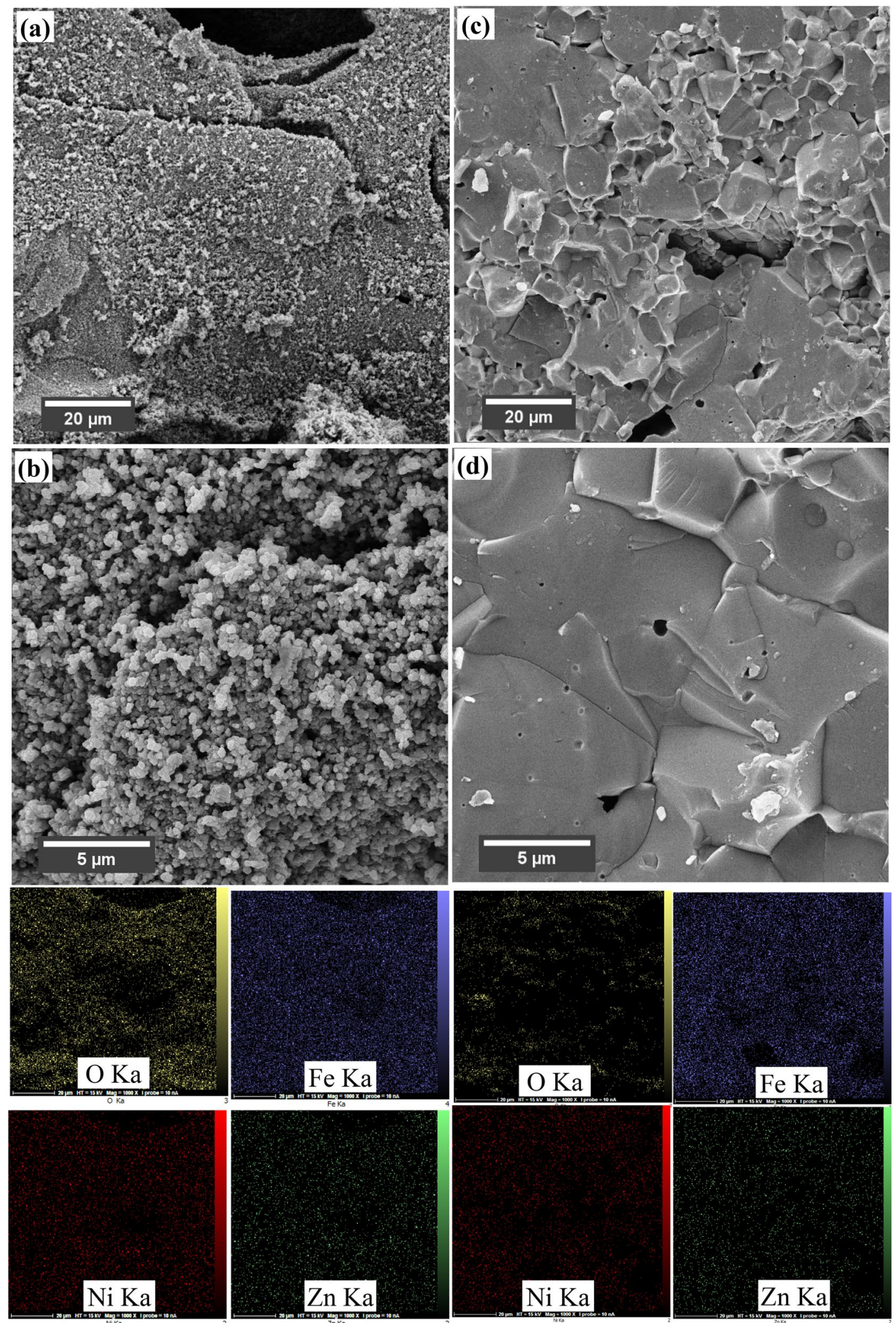

Figure 5. SEM micrographs and EDS maps of the samples sintered at (a, b) 1100 and $(\mathbf{b}, \mathbf{c}) 1300{ }^{\circ} \mathrm{C}$.

diffusion, while grain growth is ruled by GB migration. The abnormal grain growth at $1300^{\circ} \mathrm{C}$ can be attributed to the small grain size of $\mathrm{Ni}-\mathrm{Zn}$ ferrite powders, providing a large amount of activation energy for grain boundary migration. Some small pores are also trapped inside the ferrite grains because of the diffusion lag during the sintering process. Although some pores may be trapped, the resultant structure has lower defects and pores and 


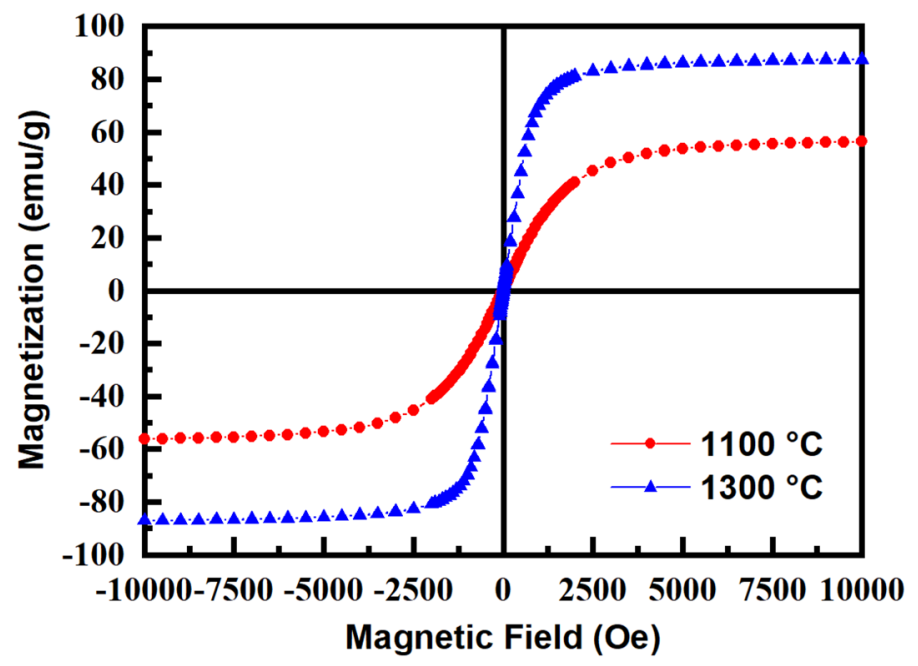

Figure 6. Magnetic hysteresis curves of the samples sintered at 1100 and $1300{ }^{\circ} \mathrm{C}$.

therefore possess more strength comparing with non-sintered structure. Moreover, with the increase of sintering temperature from 1100 to $1300{ }^{\circ} \mathrm{C}$, the density of samples increases from 4.31 to $4.92 \mathrm{~g} \mathrm{~cm}^{-3}$, respectively, which are 80.5 and \% 91.9 of theoretical density $\left(\rho_{\mathrm{XRD}}\right)$, confirming the decrease of pores and increase of the strength during sintering. Reddy et al. ${ }^{64}$ reported that the 0.5 atomic $\mathrm{Zn}$ ion enhanced the sintering and led to higher grain growth. Also, Mangalaraja et al. ${ }^{65}$ obtained the highest mechanical properties for the samples with $\mathrm{Zn}=\mathrm{Ni}=0.5$ sintered at $1350^{\circ} \mathrm{C}$. The EDAX analysis shows the various elements are uniformly distributed in the grains and grain boundaries.

Figure 6 compares the magnetization curve of the sintered samples. The samples sintered at $1100{ }^{\circ} \mathrm{C}$ have the saturation magnetization (Ms) of $56 \mathrm{emu} / \mathrm{g}$ with the coercivity $(\mathrm{Hc})$ of $12 \mathrm{Oe}$, which the coercivity decreases to $4 \mathrm{Oe}$ and the Ms increases to $87 \mathrm{emu} / \mathrm{g}$ for $1300^{\circ} \mathrm{C}$. The reduction of $\mathrm{Hc}$ can be attributed to the large grains, facilitating the magnetic domain wall motion. Also, the smooth interfaces here may decrease the Hc, according to the reports on the effect of interface roughness on increasing the $\mathrm{Hc}^{63,66}$. Aggarwal and Narang ${ }^{67}$ gained the highest Ms of about $71 \mathrm{emu} / \mathrm{g}$ and $\mathrm{Hc}$ of 35 Oe for the samples prepared by sol-gel followed by $8 \mathrm{~h}$ of heat treatment at $1000^{\circ} \mathrm{C}$. The same magnetization of $72 \mathrm{emu} / \mathrm{g}$ with a very low coercivity of 2 Oe was attained by Liu et al. ${ }^{68}$ at a higher sintering temperature of $1250^{\circ} \mathrm{C}$. The magnetization of spinel ferrites is mainly dependent on purity, crystallinity, and cations distribution between tetrahedral and octahedral sites ${ }^{46,69}$. In the collinear two sublattice model, the magnetic moments in the tetrahedral $\left(\mathrm{M}_{\mathrm{A}}\right)$ and octahedral $\left(\mathrm{M}_{B}\right)$ sites mostly determined the final magnetization value of the samples rather than the A-A and B-B exchange interactions. The most $\left|M_{A}-M_{B}\right|$ absolute difference value leads to the highest $M s$ value of the ferrite samples. $\mathrm{Zn}$ as a non-magnetic ion could modify the amount of magnetization in the ferrite sample by inducing the magnetic cation migration from tetrahedral to octahedral sites. According to Neel's theory, the high imbalance of magnetic ions such as $\mathrm{Fe}^{3+}$ and $\mathrm{Ni}^{2+}$ between (A) and [B] sites (Table 1) results in the high saturation magnetization for the sample sintered at $1300{ }^{\circ} \mathrm{C}$. The higher imbalance of $\mathrm{Fe}^{3+}$ cations for higher sintering temperatures can be attributed to the higher cooling rate ${ }^{70}$ and crystal strains. Moreover, the high crystallinity and large grains are also beneficial for the increase of Ms at higher sintering temperatures.

Figure 7 shows the permittivity $\left(\varepsilon_{\mathrm{r}}=\varepsilon^{\prime}-\mathrm{j} \varepsilon^{\prime \prime}\right)$ and permeability $\left(\mu_{\mathrm{r}}=\mu^{\prime}-\mathrm{j} \mu^{\prime \prime}\right)$ spectra of the sintered sample at $1300{ }^{\circ} \mathrm{C}$. The real parts of spectra are related to the storage of electrical and magnetic energy, while the energy dissipation is shown by imaginary parts. The values of $\varepsilon^{\prime}$ decrease versus frequency from 6 at $1 \mathrm{GHz}$ to 5.7 at $18 \mathrm{GHz}$ with an average value of about 5.8. The values of $\varepsilon^{\prime \prime}$ show two characteristic peaks at $\sim 8.5$ and $14.5 \mathrm{GHz}$ over the $1-18 \mathrm{GHz}$ range. The electrical energy of EM waves is dissipated by the conductivity and polarization mechanisms. The atomic, electronic, and dipolar polarizations are the main mechanisms of dielectric loss ${ }^{71}$. Among them, only dipolar polarizations occur in the microwave range due to the interfacial relaxations in which the accumulation of free charges at grain boundaries and defects of material enhances the dipoles ${ }^{72-74}$. The complex permittivity $\left(\varepsilon_{\mathrm{r}}\right)$ can be effectively modeled by considering the Debye equation for dipolar polarization and $\frac{\sigma}{\omega \varepsilon_{0}}$ for conductivity losses as follows ${ }^{75}$ :

$$
\varepsilon_{r}=\varepsilon^{\prime}-j \varepsilon^{\prime \prime}=\sum_{i}\left(\varepsilon_{r \infty}+\frac{\varepsilon_{r 0}-\varepsilon_{r \infty}}{1+(j \omega \tau)^{1-\alpha}}\right)_{i}-j \frac{\sigma}{\omega \varepsilon_{0}}
$$

where the first term describes the superposition of different relaxation mechanisms and the second one is related to the contribution of electrical conductivity $\left(\frac{\sigma}{\omega \varepsilon_{0}}\right)$ in which $\sigma=\sigma_{\mathrm{dc}}+\sigma_{\mathrm{ac}}$. The $\omega=2 \pi f$ is the operating angular frequency, the values of $\varepsilon_{\mathrm{r} 0 \mathrm{i}}$ and $\varepsilon_{\mathrm{r} \infty \mathrm{i}}$ are permittivity at low-frequency and high-frequency, respectively, $\tau_{\mathrm{i}}$ is the relaxation time, and $0<\alpha_{i}<1$ is a non-ideality empirical constant in $i$ th relaxation mechanism. Large ferrite grains are partially conductive, whereas grain boundaries have poor conductivity. At high-frequency ranges, large grains 

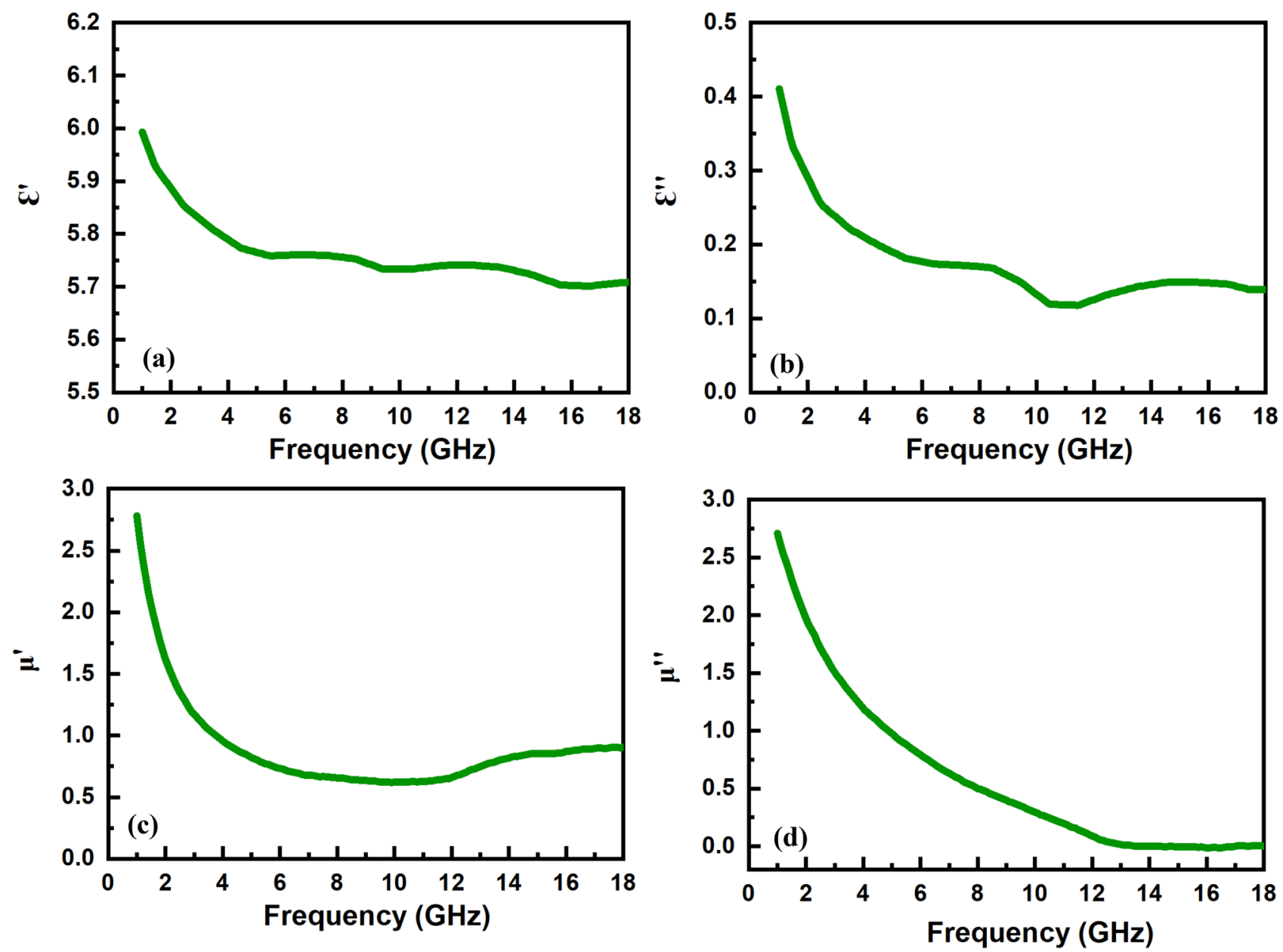

Figure 7. Permittivity and permeability spectra of the sample sintered at $1300^{\circ} \mathrm{C}$.

prevail grain boundaries which were effective at low frequencies. Also, the Maxwell-Wagner double layer model expressed that $\varepsilon^{\prime}$ is decreased and $\sigma_{\mathrm{ac}}$ is increased as frequency increased ${ }^{76}$. Therefore, the dispersive behavior of $\varepsilon^{\prime \prime}$ values with the frequency can be attributed to the higher contribution of AC conductivity $\left(\sigma_{\mathrm{ac}}\right)$. Furthermore, the peaks of $\varepsilon^{\prime \prime}$ spectra are related to the contributed relaxations, such as interfacial polarization between the ferrite grains, as can be confirmed by the Cole-Cole plot (Fig. 8a) ${ }^{77,78}$.

Figure $7 c$ and $d$ show the real and imaginary parts of permeability versus frequency. The values of $\mu^{\prime}$ and $\mu^{\prime \prime}$ decrease with the increase of frequency because of the magnetization relaxations ${ }^{79,80}$. The magnetic losses in the $\mathrm{GHz}$ region are mainly related to the eddy current and ferromagnetic resonance mechanisms ${ }^{81,82}$. The ferromagnetic resonances, including the natural resonance and wall resonance, occur in the $\mathrm{MHz}$ range for the soft magnetic NiZn spinel ferrite due to its low anisotropy field $\left(\mathrm{H}_{\mathrm{A}}\right)^{83,84}$. However, the natural resonance was observed at higher frequencies ( $\mathrm{GHz}$ range) because of the exchange resonance ${ }^{29,85,86}$. On the other hand, the eddy current effect loss can be the main mechanism in the $\mathrm{GHz}$ region for spinel ferrites. The eddy current loss is dominant when the value of $C_{0}=2 \pi t^{2} \sigma \mu_{0}=\mu^{\prime \prime}\left(\mu^{\prime}\right)^{-2} \mathrm{f}^{-1}$ is independent of frequency ${ }^{87}$. As shown in Fig. $8 \mathrm{~b}$, the $\mathrm{C}_{0}$ values are constant at above $12 \mathrm{GHz}$, indicating the predominance of the eddy current loss.

The permittivity $\left(\varepsilon_{\mathrm{r}}\right)$ and permeability $\left(\mu_{\mathrm{r}}\right)$ parameters can be used for the calculation of normalized impedance of absorber $\left(Z_{\text {in }}\right)$ relative to free space $\left(Z_{0}\right)$ and reflection loss $R L(\mathrm{~dB})$ versus frequency $(f)$ and thickness $(t)$, according to the transmission line theory as follows ${ }^{88,89}$ :

$$
\begin{gathered}
Z_{\text {in }} / Z_{0}=\sqrt{\mu_{r} / \varepsilon_{r}} \tanh \left(j(2 \pi f t / c) \sqrt{\mu_{r} \epsilon_{r}}\right) \\
R L(\mathrm{~dB})=20 \log \left|\frac{Z_{\text {in }} / Z_{0}-1}{Z_{\text {in }} / Z_{0}+1}\right|
\end{gathered}
$$

The dependency of reflection loss on the frequency and thickness is shown as a 3D contour plot in Fig. 9a. The higher magnetic and dielectric loss of EM waves by the absorber leads to a more negative RL because of the lower wave reflection from the absorber. High reflection loss up to $-48.1 \mathrm{~dB}$ is attained at the frequency range of $1-18 \mathrm{GHz}$, as shown in the 3D plot. Also, by data extraction from the plot, well-known Wireless LAN protocols of IEEE $802.11 \mathrm{~b}, \mathrm{y}$, and $\mathrm{j}$ at $\sim 2.4,3.65$, and $5 \mathrm{GHz}$ can be fully suppressed by the NiZn ferrite absorber. 

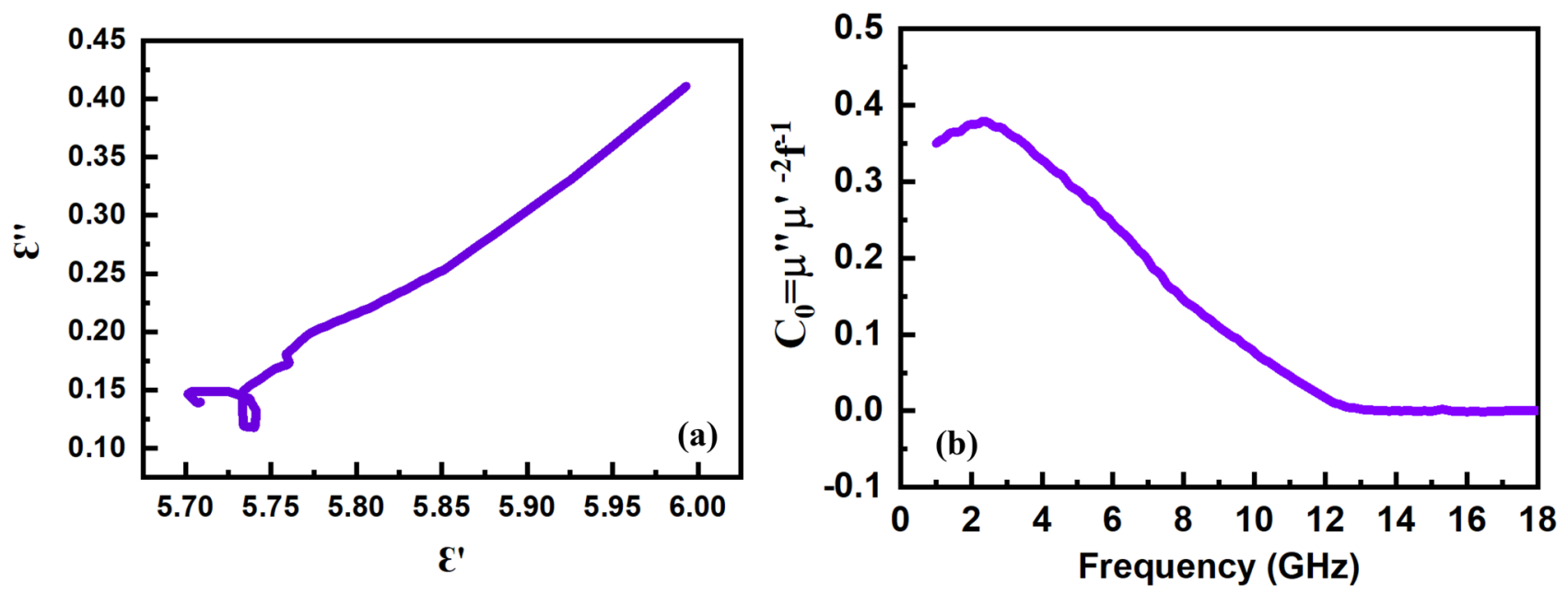

Figure 8. (a) Cole-Cole plot and (b) frequency dependence of $\mu^{\prime \prime}\left(\mu^{\prime}\right)^{-2} \mathrm{f}^{-1}$ of the sample sintered at $1300^{\circ} \mathrm{C}$.


Figure 9. (a) Reflection loss (RL) plots showing the distribution of RL versus thickness and frequency and (b) RL plots for the optimum thickness in various bands.

Furthermore, the optimum matching thickness at each frequency band was determined for obtaining the maximum RL and wide effective bandwidth (bandwidth at - $10 \mathrm{~dB}$ ), as shown in Fig. 9b. The sintered Ni-Zn ferrite showed the maximum RL of $-36.1 \mathrm{~dB}$ at the matching frequency of $10 \mathrm{GHz}$ (X-band) in the matching thickness of $3.7 \mathrm{~mm}$, having twice lesser reflection loss than that of Aggarwal and Narang ${ }^{41}$ reported at the same frequency band $(-17.54 \mathrm{~dB}$ at $9.62 \mathrm{GHz})$ and close to the Nd-doped nickel-zinc ferrite fabricated by Jiao et al. ${ }^{90}(-37 \mathrm{~dB}$ at $8.4 \mathrm{GHz}$ ). For evaluating the current study microwave absorption performance with that of other researchers, Table 3 gives a comparison by representing the composition, fabrication method, minimum reflection loss $\left(R L_{\text {min }}\right)$, matching frequency $\left(f_{m}\right)$, effecting working bandwidth (EWB), and matching thickness $\left(t_{m}\right)$ of the similar $\mathrm{Ni}-\mathrm{Zn}$ ferrite studies in the gigahertz region. The predominancy index (PI) as the ratio of effective bandwidth to matching thickness at various bands is shown in Fig. $10 \mathrm{a}^{91}$. The values of PI are $0.29,0.56,0.79,0.44$, and 0 for S, C1, C2, X, and Ku bands. The maximum effective bandwidth at the minimum matching thickness is for the $\mathrm{C} 2$ band. Mustaffa et al. ${ }^{42}$ reported the microwave absorption properties of MWCNT/ $\mathrm{Ni}_{0.5} \mathrm{Zn}_{0.5} \mathrm{Fe} 2 \mathrm{O}_{4} \mathrm{com}$ posite in the X-band and obtained the PI index of about 0.11 at the matching thickness of $3 \mathrm{~mm}$. The energy of EM waves is consumed by both dielectric and magnetic losses, can be compared by loss factor (tan $\delta$ ) versus frequency (Fig. 10b). It defines as the ratio of imaginary to real components of the complex permittivity and permeability spectra. The magnetic loss is dominant in the range of $1-12 \mathrm{GHz}$, while the dielectric loss at above $12 \mathrm{GHz}$. The magnetic loss can be attributed to the resonance mechanisms at the frequency of $1-12 \mathrm{GHz}$ and the eddy current loss at $12-18 \mathrm{GHz}$.

The total contribution of dielectric and magnetic attenuation ability can be evaluated by the attenuation constant $(\alpha)$, which is defined by the following equation ${ }^{97}$ :

$$
\alpha=\frac{\sqrt{2} \pi f}{c} \sqrt{\left(\mu^{\prime \prime} \varepsilon^{\prime \prime}-\mu^{\prime} \varepsilon^{\prime}\right)+\sqrt{\left(\mu^{\prime \prime} \varepsilon^{\prime \prime}-\mu^{\prime} \varepsilon^{\prime}\right)^{2}+\left(\mu^{\prime} \varepsilon^{\prime \prime}+\mu^{\prime \prime} \varepsilon^{\prime}\right)^{2}}}
$$

Figure 11a shows a broad peak in the frequency range of $2-12 \mathrm{GHz}$ in which the increase of $a$ values is related to the high contribution of dielectric and magnetic losses, while the strong reduction of dielectric loss results in 


\begin{tabular}{|l|l|l|l|l|l|l|}
\hline Composition & Fabrication method & $\mathbf{R L}_{\min }(\mathbf{d B})$ & $\mathbf{f}_{\mathbf{m}}(\mathbf{G H z})$ & $\mathbf{E W B}(\mathbf{G H z})$ & $\mathbf{t}_{\mathbf{m}}(\mathbf{m m})$ & References \\
\hline NZF & $\begin{array}{l}\text { Solid-State followed by sintering } \\
\text { @ } 1300^{\circ} \mathrm{C}\end{array}$ & -36.1 & 10 & 6.7 & 3.7 & Current Work \\
\hline NZF & $\begin{array}{l}\text { Solid-State followed by sintering } \\
\text { @ } 1300^{\circ} \mathrm{C}\end{array}$ & -16.9 & 7.6 & 7.1 & 4.3 & Current Work \\
\hline NZF & $\begin{array}{l}\text { Solid-State followed by sintering } \\
\text { @ } 1300^{\circ} \mathrm{C}\end{array}$ & -48.1 & 2.1 & 2.7 & 8 & Current Work \\
\hline Nd-doped NZF/PANI & $\begin{array}{l}\text { Sol-gel propagate combustion } \\
\text { (SPC) }\end{array}$ & -37.4 & 8.4 & 4.9 & 4 & 90 \\
\hline NZF/E-glass/epoxy & Sol-gel autocombustion & $-33 \mathrm{~dB}$ & 9.6 & 2.4 & 4 & 92 \\
\hline NZF/epoxy & $\begin{array}{l}\text { Sol-gel followed by annealing @ } \\
1100^{\circ} \mathrm{C}\end{array}$ & -33.64 & 10.2 & 8 & 4.1 & 51 \\
\hline Co-Zr-doped NZF & $\begin{array}{l}\text { Sol-gel citrate followed by sinter- } \\
\text { ing @ 1000 }{ }^{\circ} \mathrm{C}\end{array}$ & -44.92 & 9.2 & 2.94 & 4.25 & 93 \\
\hline NZF & followed by sintering @ 1000 ${ }^{\circ} \mathrm{C}$ & -17.54 & 9.6 & 3.1 & 3.5 & 41 \\
\hline PPy/NZF/paraffin & $\begin{array}{l}\text { Oxidative polymerization followed } \\
\text { by calcination @ 700 }{ }^{\circ} \mathrm{C}\end{array}$ & $-30 \mathrm{~dB}$ & 10.9 & 3.6 & $3 \mathrm{~mm}$ & 94 \\
\hline MWCNT/NZF & $\begin{array}{l}\text { Mechanical alloying followed by } \\
\text { sintering @ 1200 }{ }^{\circ} \mathrm{C}\end{array}$ & -19.34 & 8.46 & 1.24 & $3 \mathrm{~mm}$ & 42 \\
\hline NZF/SFO/paraffin & $\begin{array}{l}\text { Sol-gel self-propagating followed } \\
\text { by calcination @ 1000 }{ }^{\circ} \mathrm{C}\end{array}$ & $-47 \mathrm{~dB}$ & 6.2 & 6.4 & $3.5 \mathrm{~mm}$ & 95 \\
\hline Co-doped NZF/GN/paraffin & Hydrothermal & -53.5 & 9.6 & 4.8 & $3.0 \mathrm{~mm}$ & 78 \\
\hline NZF nanofiber/paraffin & Electrospinning & $-14 \mathrm{~dB}$ & 10.9 & 4.4 & $4 \mathrm{~mm}$ & 35 \\
\hline NZF/TPNR & Precipitation & -38.3 & 9.6 & 7 & $7 \mathrm{~mm}$ & 96 \\
\hline
\end{tabular}

Table 3. Microwave absorption performance of NZF tile EM absorber (current study) compared to other GHz-region NZF absorbers published articles.
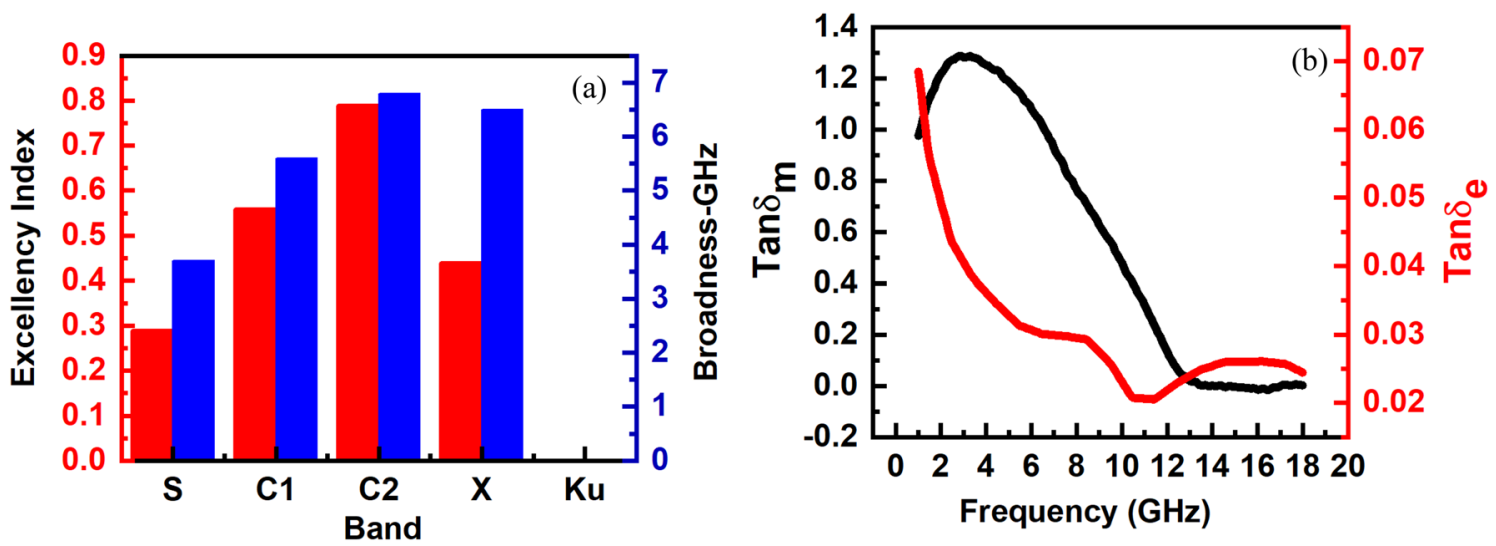

Figure 10. (a) PI index for various bands and (b) dielectric and magnetic loss versus frequency.

the decrease of $\alpha$ values at higher frequencies. The incident EM waves can penetrate the absorber with the minimum reflection when the input impedance is well-matched with free space $\left(\mathrm{Z}_{0}\right)$. In other words, the modulus of normalized impedance, $|Z|=\left|\frac{Z_{\text {in }}}{Z_{0}}\right|$, should be approached to $1^{98,99}$. Figure $11 \mathrm{~b}$ presents the normalized impedance at different matching thicknesses. It can be found that the values of $|\mathrm{Z}|$ are enough close to 1 at higher thicknesses. Therefore, the EM waves can be easily penetrated to the absorber and attenuated by magnetic and dielectric loss mechanisms.

\section{Conclusion}

Due to the emergence of wireless communications, the utilization of electromagnetic absorber materials is mandatory to reduce electromagnetic interference and bring electromagnetic compatibility for electronic devices. In this research, $\mathrm{Ni}-\mathrm{Zn}$ ferrite $\left(\mathrm{Ni}_{0.5} \mathrm{Zn}_{0.5} \mathrm{Fe}_{2} \mathrm{O}_{4}\right)$ bulk samples were fabricated to use as a tile microwave absorber material in the wide $1-18 \mathrm{GHz}$ frequency range. The sample sintered at $1300^{\circ} \mathrm{C}$ had a large grain size $(\sim 10 \mu \mathrm{m})$ with smooth grain boundaries. In addition, higher sintering temperature led to appropriate magnetic properties, including high saturation magnetization of $87 \mathrm{emu} / \mathrm{g}$ and low coercivity of 4 Oe. 3D reflection loss plot showed the distribution of loss over the $1-18 \mathrm{GHz}$ frequency range in which high reflection losses up to $-48.1 \mathrm{~dB}$ were obtained at certain low and high frequencies. The optimized condition by the preference of working bandwidth was in the range of $\sim 3$ to $10.1(7.1) \mathrm{GHz}$ for the sample with the matching thickness of $4.3 \mathrm{~mm}$ with RL of - $16.9 \mathrm{~dB}$, while by RL preference, the minimum value of $-36.1 \mathrm{~dB}$ was achieved at the thickness of $3.7 \mathrm{~mm}$ with the effective absorption bandwidth of 6.7 (4.7-11.4) GHz. The absorption performance of the sintered 



Figure 11. (a) Attenuation values versus frequency, and (b) normalized impedance versus frequency and thicknesses.

$\mathrm{Ni}-\mathrm{Zn}$ ferrite was related to easy penetration of EM waves and further attenuation by magnetic and dielectric loss mechanisms. The magnetic loss was attributed to the resonance mechanism, while the interfacial polarization was responsible for the dielectric loss.

Received: 4 February 2021; Accepted: 19 April 2021

Published online: 04 May 2021

\section{References}

1. Cao, M.-S. et al. Electronic structure and electromagnetic properties for 2D electromagnetic functional materials in gigahertz frequency. Ann. Phys. 531, 1800390. https://doi.org/10.1002/andp.201800390 (2019).

2. Lv, H. et al. A flexible microwave shield with tunable frequency-transmission and electromagnetic compatibility. Adv. Funct. Mater. 29, 1900163. https://doi.org/10.1002/adfm.201900163 (2019).

3. Ozdemir, F. \& Kargi, A. In Electromagnetic Waves Ch. 22 (ed Vitaliy, Z.) 473-492. https://doi.org/10.5772/16343 (IntechOpen, 2011).

4. Goldman, A. In Modern Ferrite Technology 273-290. https://doi.org/10.1007/978-0-387-29413-1_11 (Springer, 2006).

5. Deniz, O. G. et al. Effects of short and long term electromagnetic fields exposure on the human hippocampus. J. Microsc. Ultrastruct. 5, 191-197. https://doi.org/10.1016/j.jmau.2017.07.001 (2017).

6. Hwang, Y. Microwave absorbing properties of NiZn-ferrite synthesized from waste iron oxide catalyst. Mater. Lett. 60, 3277-3280. https://doi.org/10.1016/j.matlet.2006.03.010 (2006).

7. Kotsuka, Y. In Electromagnetic Wave Absorbers 1-15. https://doi.org/10.1002/9781119564430.ch1 (2019).

8. Tugirumubano, A., Vijay, S. J., Go, S. H., Kwac, L. K. \& Kim, H. G. Characterization of electromagnetic interference shielding composed of carbon fibers reinforced plastics and metal wire mesh based composites. J. Mark. Res. 8, 167-172. https://doi.org/10. 1016/j.jmrt.2017.08.013 (2019).

9. Jagadeesh Chandra, R. B., Shivamurthy, B., Kulkarni, S. D. \& Kumar, M. S. Hybrid polymer composites for EMI shielding application-a review. Mater. Res. Express 6, 082008. https://doi.org/10.1088/2053-1591/aaff00 (2019).

10. Zhang, Y. et al. Synthesis of broad microwave absorption bandwidth $\mathrm{Zr}^{4+}-\mathrm{Ni}^{2+}$ ions gradient-substituted barium ferrite. Ceram. Int. 46, 25808-25816. https://doi.org/10.1016/j.ceramint.2020.07.062 (2020).

11. Ibrahim, I. R. et al. A study on microwave absorption properties of carbon black and $\mathrm{Ni}_{0.6} \mathrm{Zn}_{0.4} \mathrm{Fe}_{2} \mathrm{O}_{4}$ nanocomposites by tuning the matching-absorbing layer structures. Sci. Rep. 10, 3135. https://doi.org/10.1038/s41598-020-60107-1 (2020).

12. Harris, V. G. Modern microwave ferrites. IEEE Trans. Magn. 48, 1075-1104. https://doi.org/10.1109/TMAG.2011.2180732 (2012).

13. Idris, F. M. et al. Recent developments of smart electromagnetic absorbers based polymer-composites at gigahertz frequencies. J. Magn. Magn. Mater. 405, 197-208. https://doi.org/10.1016/j.jmmm.2015.12.070 (2016).

14. Green, M. et al. Doped, conductive $\mathrm{SiO}_{2}$ nanoparticles for large microwave absorption. Light Sci. Appl. 7, 87. https://doi.org/10. 1038/s41377-018-0088-8 (2018).

15. Chang, Y. et al. Microwave absorption in $0.1-18 \mathrm{GHz}$, magnetic and structural properties of $\mathrm{SrFe}_{12-\mathrm{x}} \mathrm{Ru}_{\mathrm{x}} \mathrm{O}_{19}$ and $\mathrm{BaFe}_{12-\mathrm{x}} \mathrm{Ru}_{\mathrm{x}} \mathrm{O}_{19}$. J. Alloys Compd. 818, 152930. https://doi.org/10.1016/j.jallcom.2019.152930 (2020).

16. Wu, Z. et al. Hierarchically porous carbons derived from biomasses with excellent microwave absorption performance. ACS Appl. Mater. Interfaces 10, 11108-11115. https://doi.org/10.1021/acsami.7b17264 (2018).

17. Bhattacharyya, R. et al. Graphene oxide-ferrite hybrid framework as enhanced broadband absorption in gigahertz frequencies. Sci. Rep. 9, 12111. https://doi.org/10.1038/s41598-019-48487-5 (2019).

18. Sebastian, M. T., Ubic, R. \& Jantunen, H. Microwave Materials and Applications Vol. 2 (Wiley, 2017).

19. Krishnaveni, T., Kanth, B. R., Raju, V. S. R. \& Murthy, S. R. Fabrication of multilayer chip inductors using Ni-Cu-Zn ferrites. J. Alloys Compd. 414, 282-286. https://doi.org/10.1016/j.jallcom.2005.07.029 (2006).

20. Dalawai, S. P., Shinde, T. J., Gadkari, A. B. \& Vasambekar, P. N. Ni-Zn ferrite thick film gas sensors. J. Mater. Sci. Mater. Electron. 26, 9016-9025. https://doi.org/10.1007/s10854-015-3585-z (2015).

21. Kharat, P. B., Somvanshi, S. B., Khirade, P. P. \& Jadhav, K. M. Induction heating analysis of surface-functionalized nanoscale $\mathrm{CoFe}_{2} \mathrm{O}_{4}$ for magnetic fluid hyperthermia toward noninvasive cancer treatment. ACS Omega 5, 23378-23384. https://doi.org/10. 1021/acsomega.0c03332 (2020).

22. Patade, S. R., Andhare, D. D., Somvanshi, S. B., Kharat, P. B. \& Jadhav, K. M. Effect of zinc doping on water-based manganese ferrite nanofluids for magnetic hyperthermia application. AIP Conf. Proc. 2265, 030557. https://doi.org/10.1063/5.0017051 (2020).

23. Somvanshi, S. B., Kumar, R. V., Kounsalye, J. S., Saraf, T. S. \& Jadhav, K. M. Investigations of structural, magnetic and induction heating properties of surface functionalized zinc ferrite nanoparticles for hyperthermia applications. AIP Conf. Proc. 2115, 030522. https://doi.org/10.1063/1.5113361 (2019). 
24. Jadhav, S. A., Somvanshi, S. B., Khedkar, M. V., Patade, S. R. \& Jadhav, K. M. Magneto-structural and photocatalytic behavior of mixed Ni-Zn nano-spinel ferrites: visible light-enabled active photodegradation of rhodamine B. J. Mater. Sci. Mater. Electron. 31, 11352-11365. https://doi.org/10.1007/s10854-020-03684-1 (2020).

25. Borade, R. M., Somvanshi, S. B., Kale, S. B., Pawar, R. P. \& Jadhav, K. M. Spinel zinc ferrite nanoparticles: an active nanocatalyst for microwave irradiated solvent free synthesis of chalcones. Mater. Res. Express 7, 016116. https://doi.org/10.1088/2053-1591/ ab6c9c (2020).

26. Hölscher, J., Andersen, H. L., Saura-Múzquiz, M., Garbus, P. G. \& Christensen, M. Correlation between microstructure, cation distribution and magnetism in $\mathrm{Ni}_{1-\mathrm{x}} \mathrm{Zn}_{\mathrm{x}} \mathrm{Fe}_{2} \mathrm{O}_{4}$ nanocrystallites. CrystEngComm 22, 515-524. https://doi.org/10.1039/C9CE01324E (2020).

27. Thakur, P., Chahar, D., Taneja, S., Bhalla, N. \& Thakur, A. A review on MnZn ferrites: synthesis, characterization and applications. Ceram. Int. 46, 15740-15763. https://doi.org/10.1016/j.ceramint.2020.03.287 (2020).

28. Nakamura, T., Tsutaoka, T. \& Hatakeyama, K. Frequency dispersion of permeability in ferrite composite materials. J. Magn. Magn. Mater. 138, 319-328. https://doi.org/10.1016/0304-8853(94)90054-X (1994).

29. Nakamura, T. Snoek's limit in high-frequency permeability of polycrystalline $\mathrm{Ni}-\mathrm{Zn}, \mathrm{Mg}-\mathrm{Zn}$, and Ni-Zn-Cu spinel ferrites. J. Appl. Phys. 88, 348-353. https://doi.org/10.1063/1.373666 (2000).

30. Massoudi, J. et al. Magnetic and spectroscopic properties of $\mathrm{Ni}-\mathrm{Zn}-\mathrm{Al}$ ferrite spinel: from the nanoscale to microscale. RSC Adv. 10, 34556-34580. https://doi.org/10.1039/D0RA05522K (2020).

31. Masoudpanah, S. M., Seyyed Ebrahimi, S. A., Derakhshani, M. \& Mirkazemi, S. M. Structure and magnetic properties of La substituted $\mathrm{ZnFe}_{2} \mathrm{O}_{4}$ nanoparticles synthesized by sol-gel autocombustion method. J. Magn. Magn. Mater. 370, 122-126. https://doi. org/10.1016/j.jmmm.2014.06.062 (2014).

32. Ahmed, T. T., Rahman, I. Z. \& Rahman, M. A. Study on the properties of the copper substituted NiZn ferrites. J. Mater. Process. Technol. 153-154, 797-803. https://doi.org/10.1016/j.jmatprotec.2004.04.188 (2004).

33. Naughton, B. T. \& Clarke, D. R. Lattice expansion and saturation magnetization of nickel-zinc ferrite nanoparticles prepared by aqueous precipitation. J. Am. Ceram. Soc. 90, 3541-3546. https://doi.org/10.1111/j.1551-2916.2007.01980.x (2007).

34. Sivakumar, N., Narayanasamy, A., Ponpandian, N. \& Govindaraj, G. Grain size effect on the dielectric behavior of nanostructured $\mathrm{Ni}_{0.5} \mathrm{Zn}_{0.5} \mathrm{Fe}_{2} \mathrm{O}_{4}$. J. Appl. Phys. 101, 084116. https://doi.org/10.1063/1.2721379 (2007).

35. Huang, X., Zhang, J., Lai, M. \& Sang, T. Preparation and microwave absorption mechanisms of the NiZn ferrite nanofibers. J. Alloys Compd. 627, 367-373. https://doi.org/10.1016/j.jallcom.2014.11.235 (2015).

36. Naughton, B. T., Majewski, P. \& Clarke, D. R. Magnetic properties of nickel-zinc ferrite toroids prepared from nanoparticles. J. Am. Ceram. Soc. 90, 3547-3553. https://doi.org/10.1111/j.1551-2916.2007.01981.x (2007).

37. Song, S., Song, Q., Li, J., Mudinepalli, V. R. \& Zhang, Z. Characterization of submicrometer-sized NiZn ferrite prepared by spark plasma sintering. Ceram. Int. 40, 6473-6479. https://doi.org/10.1016/j.ceramint.2013.11.099 (2014).

38. Sung-Soo, K., Dae-Hee, H. \& Sung-Baeg, C. Microwave absorbing properties of sintered Ni-Zn ferrite. IEEE Trans. Magn. 30, 4554-4556. https://doi.org/10.1109/20.334146 (1994).

39. Kakirde, A., Sinha, B. \& Sinha, S. N. Development and characterization of nickel-zinc spinel ferrite for microwave absorption at 2.4 GHz. Bull. Mater. Sci. 31, 767-770. https://doi.org/10.1007/s12034-008-0121-2 (2008).

40. Prasath, S. D. R., Balaji, S., Raju, S. \& Abhaikumar, V. Synthesis and characterization of zinc substituted nickel ferrite materials for L band antenna applications. J. Mater. Sci. Mater. Electron. 27, 8247-8253. https://doi.org/10.1007/s10854-016-4831-8 (2016).

41. Aggarwal, N. \& Narang, S. B. X-band microwave analysis and characterization of zinc substituted nickel ferrites prepared by sol-gel citrate route. J. Electron. Mater. 49, 668-680. https://doi.org/10.1007/s11664-019-07694-6 (2020).

42. Mustaffa, M. S., Azis, R. A. S., Abdullah, N. H., Ismail, I. \& Ibrahim, I. R. An investigation of microstructural, magnetic and microwave absorption properties of multi-walled carbon nanotubes $/ \mathrm{Ni}_{0.5} \mathrm{Zn}_{0.5} \mathrm{Fe}_{2} \mathrm{O}_{4}$. Sci. Rep. 9, 15523. https://doi.org/10.1038/ s41598-019-52233-2 (2019).

43. Jahanbin, T., Hashim, M. \& Amin Mantori, K. Comparative studies on the structure and electromagnetic properties of Ni- $\mathrm{Zn}$ ferrites prepared via co-precipitation and conventional ceramic processing routes. J. Magn. Magn. Mater. 322, 2684-2689. https:// doi.org/10.1016/j.jmmm.2010.04.008 (2010).

44. Hajalilou, A., Mazlan, S. A. \& Shameli, K. A comparative study of different concentrations of pure Zn powder effects on synthesis, structure, magnetic and microwave-absorbing properties in mechanically-alloyed Ni-Zn ferrite. J. Phys. Chem. Solids 96-97, 49-59. https://doi.org/10.1016/j.jpcs.2016.05.001 (2016).

45. Andhare, D. D. et al. Structural and chemical properties of $\mathrm{ZnFe}_{2} \mathrm{O}_{4}$ nanoparticles synthesised by chemical co-precipitation technique. J. Phys. Conf. Ser. 1644, 012014. https://doi.org/10.1088/1742-6596/1644/1/012014 (2020).

46. Verma, R., Mazaleyrat, F., Deshpande, U. P. \& Kane, S. N. Ni addition induced modification of structural, magnetic properties and bandgap of Ni-Zn nano ferrites. Mater. Today Proc. 32, 329-333. https://doi.org/10.1016/j.matpr.2020.01.489 (2020).

47. Idris, F. M. et al. Broadening of EM energy-absorption frequency band by micrometer-to-nanometer grain size reduction in NiZn ferrite. IEEE Trans. Magn. 49, 5475-5479. https://doi.org/10.1109/TMAG.2013.2271219 (2013).

48. Lakshmi, K., John, H., Mathew, K. T., Joseph, R. \& George, K. E. Microwave absorption, reflection and EMI shielding of PU-PANI composite. Acta Mater. 57, 371-375. https://doi.org/10.1016/j.actamat.2008.09.018 (2009).

49. Wang, G., Ong, S. J. H., Zhao, Y., Xu, Z. J. \& Ji, G. Integrated multifunctional macrostructures for electromagnetic wave absorption and shielding. J. Mater. Chem. A 8, 24368-24387. https://doi.org/10.1039/D0TA08515D (2020).

50. Shimba, K., Furuta, K., Morimoto, N., Tezuka, N. \& Sugimoto, S. Microwave absorption properties of polymer modified Ni-Zn ferrite nanoparticles. Mater. Trans. 52, 740-745. https://doi.org/10.2320/matertrans.MBW201013 (2011).

51. Yoo, J.-E. \& Kang, Y.-M. Electromagnetic wave absorbing properties of $\mathrm{Ni}-\mathrm{Zn}$ ferrite powder-epoxy composites in $\mathrm{GHz}$ range. J. Magn. Magn. Mater. 513, 167075. https://doi.org/10.1016/j.jmmm.2020.167075 (2020).

52. Naidu, K. C. B. \& Madhuri, W. Microwave processed bulk and nano NiMg ferrites: a comparative study on X-band electromagnetic interference shielding properties. Mater. Chem. Phys. 187, 164-176. https://doi.org/10.1016/j.matchemphys.2016.11.062 (2017).

53. Izumi, F. In Analytical Spectroscopy Library Vol. 7 (eds Saisho, H. \& Gohshi, Y.) 405-452. https://doi.org/10.1016/S0926-4345(96) 80008-3(Elsevier, 1996).

54. Somvanshi, S. B. et al. Structural, thermal, spectral, optical and surface analysis of rare earth metal ion $\left(\mathrm{Gd}^{3+}\right)$ doped mixed $\mathrm{Zn}-\mathrm{Mg}$ nano-spinel ferrites. Ceram. Int. 46, 13170-13179. https://doi.org/10.1016/j.ceramint.2020.02.091 (2020).

55. Jalaly, M., Enayati, M. H. \& Karimzadeh, F. Investigation of structural and magnetic properties of nanocrystalline $\mathrm{Ni}_{0.3} \mathrm{Zn}_{0.7} \mathrm{Fe}_{2} \mathrm{O}_{4}$ prepared by high energy ball milling. J. Alloys Compd. 480, 737-740. https://doi.org/10.1016/j.jallcom.2009.02.042 (2009).

56. Bid, S. \& Pradhan, S. K. Characterization of crystalline structure of ball-milled nano-Ni-Zn-ferrite by Rietveld method. Mater. Chem. Phys. 84, 291-301. https://doi.org/10.1016/j.matchemphys.2003.08.012 (2004).

57. Somvanshi, S. B., Khedkar, M. V., Kharat, P. B. \& Jadhav, K. M. Influential diamagnetic magnesium $\left(\mathrm{Mg}^{2+}\right)$ ion substitution in nano-spinel zinc ferrite $\left(\mathrm{ZnFe}_{2} \mathrm{O}_{4}\right)$ : thermal, structural, spectral, optical and physisorption analysis. Ceram. Int. 46, 8640-8650. https://doi.org/10.1016/j.ceramint.2019.12.097 (2020).

58. Ehi-Eromosele, C. O., Ita, B. I., Iweala, E. E., Adalikwu, S. A. \& Anawe, L. P. A. Magneto-structural properties of Ni-Zn nanoferrites synthesized by the low-temperature auto-combustion method. Bull. Mater. Scie. 38, 1465-1472. https://doi.org/10.1007/ s12034-015-1038-1 (2015).

59. Wang, Z., Schiferl, D., Zhao, Y. \& O’Neill, H. S. C. High pressure Raman spectroscopy of spinel-type ferrite $\mathrm{ZnFe}_{2} \mathrm{O}_{4}$. J. Phys. Chem. Solids 64, 2517-2523. https://doi.org/10.1016/j.jpcs.2003.08.005 (2003). 
60. Cynn, H., Sharma, S. K., Cooney, T. F. \& Nicol, M. High-temperature Raman investigation of order-disorder behavior in the $\mathrm{MgAl}_{2} \mathrm{O}_{4}$ spinel. Phys. Rev. B 45, 500-502. https://doi.org/10.1103/PhysRevB.45.500 (1992).

61. Wang, Z., Lazor, P., Saxena, S. K. \& O’Neill, H. S. C. High pressure Raman spectroscopy of ferrite $\mathrm{MgFe}_{2} \mathrm{O}_{4}$. Mater. Res. Bull. 37, 1589-1602. https://doi.org/10.1016/S0025-5408(02)00819-X (2002).

62. Ma, Y. et al. Tunable microwave absorption property of magnetic nanocomposite coating by surface roughness. J. Mater. Sci. Mater. Electron. 31, 994-1003. https://doi.org/10.1007/s10854-019-02611-3 (2020).

63. Arboleda, J. D. et al. Evidence of the spin Seebeck effect in Ni-Zn ferrites polycrystalline slabs. Solid State Commun. 270, 140-146. https://doi.org/10.1016/j.ssc.2017.12.002 (2018).

64. Reddy, M. P. et al. Magnetic properties of Ni-Zn ferrites prepared by microwave sintering method. J. Electroceram. 28, 1-9. https:// doi.org/10.1007/s10832-011-9670-7 (2012).

65. Mangalaraja, R. V., Lee, S. T., Ramam, K. V. S., Ananthakumar, S. \& Manohar, P. Mechanical characterization of $\mathrm{Ni}_{1-\mathrm{x}} \mathrm{Zn}_{\mathrm{x}} \mathrm{Fe}_{2} \mathrm{O}_{4}$ prepared by non-conventional methods. Mater. Sci. Eng. A 480, 266-270. https://doi.org/10.1016/j.msea.2007.08.021 (2008).

66. Aqeel, A. et al. Surface sensitivity of the spin Seebeck effect. J. Appl. Phys. 116, 153705. https://doi.org/10.1063/1.4897933 (2014).

67. Aggarwal, N. \& Narang, S. B. Magnetic characterization of nickel-zinc spinel ferrites along with their microwave characterization in Ku band. J. Magn. Magn. Mater. 513, 167052. https://doi.org/10.1016/j.jmmm.2020.167052 (2020).

68. Liu, Z., Peng, Z., Lv, C. \& Fu, X. Doping effect of $\mathrm{Sm}^{3+}$ on magnetic and dielectric properties of Ni-Zn ferrites. Ceram. Int. 43, 1449-1454. https://doi.org/10.1016/j.ceramint.2016.10.112 (2017).

69. Humbe, A. V., Kounsalye, J. S., Somvanshi, S. B., Kumar, A. \& Jadhav, K. M. Cation distribution, magnetic and hyperfine interaction studies of Ni-Zn spinel ferrites: role of Jahn Teller ion $\left(\mathrm{Cu}^{2+}\right)$ substitution. Mater. Adv. 1, 880-890. https://doi.org/10.1039/ D0MA00251H (2020).

70. Guire, M. R. D., O’Handley, R. C. \& Kalonji, G. The cooling rate dependence of cation distributions in $\mathrm{CoFe}_{2} \mathrm{O}_{4}$. J. Appl. Phys. 65, 3167-3172. https://doi.org/10.1063/1.342667 (1989).

71. Chen, L. F., Ong, C. K., Neo, C. P., Varadan, V. V. \& Varadan, V. K. In Microwave Electronics: Measurement and Materials Characterization Ch. 1, 1-36. https://doi.org/10.1002/0470020466.ch1(Wiley, 2004).

72. Jazirehpour, M. \& Ebrahimi, S. A. S. Synthesis of magnetite nanostructures with complex morphologies and effect of these morphologies on magnetic and electromagnetic properties. Ceram. Int. 42, 16512-16520. https://doi.org/10.1016/j.ceramint.2016.07. 067 (2016).

73. Wan, G. et al. Uniform $\mathrm{Fe}_{3} \mathrm{O}_{4}$ coating on flower-like $\mathrm{ZnO}$ nanostructures by atomic layer deposition for electromagnetic wave absorption. Dalton Trans. 44, 18804-18809. https://doi.org/10.1039/C5DT03069B (2015).

74. Lopes, B. H. K. et al. X band electromagnetic property influence of multi-walled carbon nanotube in hybrid $\mathrm{MnZn}$ ferrite and carbonyl iron composites. J. Mark. Res. 9, 2369-2375. https://doi.org/10.1016/j.jmrt.2019.12.068 (2020).

75. Heidari, P. \& Masoudpanah, S. M. A facial synthesis of $\mathrm{MgFe}_{2} \mathrm{O}_{4} / \mathrm{RGO}$ nanocomposite powders as a high performance microwave absorber. J. Alloys Compd. 834, 155166. https://doi.org/10.1016/j.jallcom.2017.12.179 (2020).

76. Abdeen, A. M. Dielectric behaviour in Ni-Zn ferrites. J. Magn. Magn. Mater. 192, 121-129. https://doi.org/10.1016/S0304-8853(98) 00324-2 (1999).

77. Jian, X. et al. Facile synthesis of $\mathrm{Fe}_{3} \mathrm{O}_{4} / \mathrm{GCs}$ composites and their enhanced microwave absorption properties. ACS Appl. Mater. Interfaces 8, 6101-6109. https://doi.org/10.1021/acsami.6b00388 (2016).

78. Liu, P., Yao, Z., Zhou, J., Yang, Z. \& Kong, L. B. Small magnetic Co-doped NiZn ferrite/graphene nanocomposites and their dualregion microwave absorption performance. J. Mater. Chem. C 4, 9738-9749. https://doi.org/10.1039/C6TC03518C (2016).

79. Sun, K. et al. Contribution of magnetization mechanisms in nickel-zinc ferrites with different grain sizes and its temperature relationship. Mater. Chem. Phys. 175, 131-137. https://doi.org/10.1016/j.matchemphys.2016.03.002 (2016).

80. Barba, A., Clausell, C., Jarque, J. C. \& Nuño, L. Magnetic complex permeability (imaginary part) dependence on the microstructure of a Cu-doped Ni-Zn-polycrystalline sintered ferrite. Ceram. Int. 46, 14558-14566. https://doi.org/10.1016/j.ceramint.2020.02. $255(2020)$.

81. Song, N.-N. et al. Exceeding natural resonance frequency limit of monodisperse $\mathrm{Fe}_{3} \mathrm{O}_{4}$ nanoparticles via superparamagnetic relaxation. Sci. Rep. 3, 3161. https://doi.org/10.1038/srep03161 (2013).

82. Fu, L.-S., Jiang, J.-T., Xu, C.-Y. \& Zhen, L. Synthesis of hexagonal Fe microflakes with excellent microwave absorption performance. CrystEngComm 14, 6827-6832. https://doi.org/10.1039/C2CE25836F (2012).

83. Nakamura, T. Low-temperature sintering of NiZnCu ferrite and its permeability spectra. J. Magn. Magn. Mater. 168, 285-291. https://doi.org/10.1016/S0304-8853(96)00709-3 (1997).

84. Li, J., Ji, H., Xu, Y., Zhang, J. \& Yan, Y. Three-dimensional graphene supported $\mathrm{Fe}_{3} \mathrm{O}_{4}$ coated by polypyrrole toward enhanced stability and microwave absorbing properties. J. Mark. Res. 9, 762-772. https://doi.org/10.1016/j.jmrt.2019.11.016 (2020).

85. Caltun, O. F., Spinu, L., Stancu, A., Thung, L. D. \& Zhou, W. Study of the microstructure and of the permeability spectra of NiZn-Cu ferrites. J. Magn. Magn. Mater. 242-245, 160-162. https://doi.org/10.1016/S0304-8853(01)01187-8 (2002).

86. He, J.-Z., Wang, X.-X., Zhang, Y.-L. \& Cao, M.-S. Small magnetic nanoparticles decorating reduced graphene oxides to tune the electromagnetic attenuation capacity. J. Mater. Chem. C 4, 7130-7140. https://doi.org/10.1039/C6TC02020H (2016).

87. Wang, H. et al. Broadband microwave absorption of CoNi@C nanocapsules enhanced by dual dielectric relaxation and multiple magnetic resonances. Appl. Phys. Lett. 102, 223113. https://doi.org/10.1063/1.4809675 (2013).

88. Kwon, H. J., Shin, J. Y. \& Oh, J. H. The microwave absorbing and resonance phenomena of Y-type hexagonal ferrite microwave absorbers. J. Appl. Phys. 75, 6109-6111. https://doi.org/10.1063/1.355476 (1994).

89. Shin, J. Y. \& Oh, J. H. The microwave absorbing phenomena of ferrite microwave absorbers. IEEE Trans. Magn. 29, 3437-3439. https://doi.org/10.1109/20.281188 (1993).

90. Jiao, Z. et al. Enhanced microwave absorption properties of Nd-doped NiZn ferrite/polyaniline nanocomposites. Ceram. Int. https://doi.org/10.1016/j.ceramint.2020.07.010 (2020).

91. Jazirehpour, M. \& Seyyed Ebrahimi, S. A. Carbothermally synthesized core-shell carbon-magnetite porous nanorods for highperformance electromagnetic wave absorption and the effect of the heterointerface. J. Alloys Compd. 639, 280-288. https://doi. org/10.1016/j.jallcom.2015.03.160 (2015).

92. Siva Nagasree, P., Ramji, K., Subramanyam, C., Krushnamurthy, K. \& Haritha, T. Synthesis of $\mathrm{Ni}_{0.5} \mathrm{Zn}_{0.5} \mathrm{Fe}_{2} \mathrm{O}_{4}$-reinforced E-glass/ epoxy nanocomposites for radar-absorbing structures. Plast. Rubber Compos. 49, 434-442. https://doi.org/10.1080/14658011.2020. 1793080 (2020).

93. Aggarwal, N. \& Narang, S. B. Effect of co-substitution of Co-Zr on electromagnetic properties of Ni-Zn spinel ferrites at microwave frequencies. J. Alloys Compd. https://doi.org/10.1016/j.jallcom.2020.157461 (2020).

94. Ali, N. N. et al. Lightweight broadband microwave absorbers of core-shell (polypyrrole/NiZn ferrite) nanocomposites in the X-band: insights on interfacial polarization. J. Mater. Sci. Mater. Electron. 30, 6876-6887. https://doi.org/10.1007/s10854-01901002-y (2019).

95. Han, Q., Meng, X. \& Lu, C. Exchange-coupled $\mathrm{Ni}_{0.5} \mathrm{Zn}_{0.5} \mathrm{Fe}_{2} \mathrm{O}_{4} / \mathrm{SrFe}_{12} \mathrm{O}_{19}$ composites with enhanced microwave absorption performance. J. Alloys Compd. 768, 742-749. https://doi.org/10.1016/j.jallcom.2018.07.310 (2018).

96. Flaifel, M. H. et al. Preparation, thermal, magnetic and microwave absorption properties of thermoplastic natural rubber matrix impregnated with NiZn ferrite nanoparticles. Compos. Sci. Technol. 96, 103-108. https://doi.org/10.1016/j.compscitech.2014.03. 016 (2014). 
97. Li, X. et al. Fabrication of three-dimensional flower-like heterogeneous $\mathrm{Fe}_{3} \mathrm{O}_{4} / \mathrm{Fe}$ particles with tunable chemical composition and microwave absorption performance. ACS Appl. Mater. Interfaces 11, 19267-19276. https://doi.org/10.1021/acsami.9b01783 (2019).

98. Yan, F. et al. Growth of $\mathrm{CoFe}_{2} \mathrm{O}_{4}$ hollow nanoparticles on graphene sheets for high-performance electromagnetic wave absorbers. J. Mater. Chem. C 6, 12781-12787. https://doi.org/10.1039/C8TC04222E (2018).

99. Li, D., Zhang, B., Liu, W., Liang, X. \& Ji, G. Tailoring the input impedance of $\mathrm{FeCo} / \mathrm{C}$ composites with efficient broadband absorption. Dalton Trans. 46, 14926-14933. https://doi.org/10.1039/C7DT02840G (2017).

\section{Author contributions}

All authors have contributed to the present research. M.D.: Synthesis, Characterization, Conceptualization, Writing the manuscript text and preparing figures. E.T.-N.: Supervision, Review and editing the main manuscript, Conceptualization. M.J.: Supervision, Characterization. S.M.M.: Supervision, Conceptualization, Reviewing and editing the manuscript text and figures. All authors approved the final manuscript.

\section{Competing interests}

The authors declare no competing interests.

\section{Additional information}

Correspondence and requests for materials should be addressed to E.T.-N.

Reprints and permissions information is available at www.nature.com/reprints.

Publisher's note Springer Nature remains neutral with regard to jurisdictional claims in published maps and institutional affiliations.

(c) (i) Open Access This article is licensed under a Creative Commons Attribution 4.0 International cc) License, which permits use, sharing, adaptation, distribution and reproduction in any medium or format, as long as you give appropriate credit to the original author(s) and the source, provide a link to the Creative Commons licence, and indicate if changes were made. The images or other third party material in this article are included in the article's Creative Commons licence, unless indicated otherwise in a credit line to the material. If material is not included in the article's Creative Commons licence and your intended use is not permitted by statutory regulation or exceeds the permitted use, you will need to obtain permission directly from the copyright holder. To view a copy of this licence, visit http://creativecommons.org/licenses/by/4.0/.

(C) The Author(s) 2021 